\title{
Early postnatal dexamethasone treatment and increased incidence of cerebral palsy
} E S Shinwell, M Karplus, D Reich, Z Weintraub, S Blazer, D Bader, S Yurman, T Dolfin,
A Kogan, S Dollberg, E Arbel, M Goldberg, I Gur, N Naor, L Sirota, S Mogilner, A Zaritsky, M Barak, E Gottfried

Kaplan Medical

Center, Rechovot, Israel

E S Shinwell

S Mogilner

Soroka Medical Center, Beersheva M Karplus

Ha'emek Medical Center, Afula

D Reich

Carmel Medical Center, Haifa Z Weintraub

Rambam Medical Center, Haifa $S$ Blazer

Bnei-Zion Medical Center, Haifa D Bader

Hillel Yaffe Medical Center, Hadera $S$ Yurman

Meir Medical Center, Kfar Saba

T Dolfin

Sheba Medical Center, Tel Hashomer A Kogan

Tel Aviv Medical Center, Tel Aviv S Dollberg

Wolfson Medical Center, Holon

E Arbel

Assaf Harofe Medical Center, Tsrifin

M Goldberg

Bikur Holim Medical Center, Jerusalem

I Gur

Beilinson Medical Center, Petach Tikva N Naor

L Sirota

Barzilai Medical Center, Ashkelon A Zaritsky

Nahariya Regional Medical Center M Barak

Rivka Ziv Medical Center, Tsfat

E Gottfried

Correspondence to: Dr Shinwell, Department of Neonatology, Kaplan Medical Center, Rechovot, Israel

shinwell@ netvision.net.il

Accepted 14 June 2000

\begin{abstract}
Objective-To study the long term neurodevelopmental outcome of children who participated in a randomised, double blind, placebo controlled study of early postnatal dexamethasone treatment for prevention of chronic lung disease.

Methods-The original study compared a three day course of dexamethasone $(n=132)$ with a saline placebo $(n=116)$ administered from before 12 hours of age in preterm infants, who were ventilated for respiratory distress syndrome and had received surfactant treatment. Dexamethasone treatment was associated with an increased incidence of hypertension, hyperglycaemia, and gastrointestinal haemorrhage and no reduction in either the incidence or severity of chronic lung disease or mortality. A total of 195 infants survived to discharge and five died later. Follow up data were obtained on 159 of 190 survivors at a mean (SD) age of 53 (18) months.
\end{abstract}

Results-No differences were found between the groups in terms of perinatal or neonatal course, antenatal steroid administration, severity of initial disease, or major neonatal morbidity. Dexamethasone treated children had a significantly higher incidence of cerebral palsy than those receiving placebo $(39 / 80(49 \%) v$ $12 / 79(15 \%)$ respectively; odds ratio (OR) $4.62,95 \%$ confidence interval $(95 \% \mathrm{CI})$ 2.38 to 8.98 ). The most common form of cerebral palsy was spastic diplegia (incidence $22 / 80(28 \%) v 5 / 79(6 \%)$ in dexamethasone and placebo treated infants respectively; OR $4.45,95 \%$ CI 1.95 to 10.15). Developmental delay was significantly more common in the dexamethasone treated group $(44 / 80(55 \%))$ than in the placebo treated group (23/79 (29\%); OR $2.87,95 \%$ CI 1.53 to 5.38). Dexamethasone treated infants had more periventricular leucomalacia and less intraventricular haemorrhage in the neonatal period than those in the placebo group, although these differences were not statistically significant. Eleven children with cerebral palsy had normal ultrasound scans in the neonatal period; all 11 had received dexamethasone. Logistic regression analysis showed both periventricular leucomalacia and drug assignment to dexamethasone to be highly significant predictors of abnormal neurological outcome.
Conclusions-A three day course of dexamethasone administered shortly after birth in preterm infants with respiratory distress syndrome is associated with a significantly increased incidence of cerebral palsy and developmental delay.

(Arch Dis Child Fetal Neonatal Ed 2000;83:F177-F181)

Keywords: dexamethasone; steroids; chronic lung disease; bronchopulmonary dysplasia; cerebral palsy

Early postnatal dexamethasone treatment is widely used for the prevention and treatment of chronic lung disease in premature infants. ${ }^{1}$ However, the results of clinical trials have been contradictory as to the effect on short term respiratory status and mortality. ${ }^{2-11}$ Recently, follow up studies have raised the possibility that early postnatal dexamethasone treatment may be associated with an adverse effect on subsequent neuromotor function and somatic growth. ${ }^{12}{ }^{13}$

We have previously reported a randomised, double blind, placebo controlled trial of a three day course of dexamethasone begun before 12 hours of age in premature infants with respiratory distress syndrome. ${ }^{2}$ We now report the neurological and developmental status of these infants at up to 6 years of age.

\section{Methods}

BRIEF DESCRIPTION OF ORIGINAL STUDY

This was a randomised, double blind, placebo controlled study that was conducted in 18 neonatal intensive care units in Israel between March 1993 and January 1994. ${ }^{2}$ Approval for the study was obtained from individual institutional review boards and from the Israeli Ministry of Health. Inclusion criteria were: clinical and radiographic diagnosis of respiratory distress syndrome; requiring mechanical ventilation and $\mathrm{FIO}_{2}>0.4$ with a $\mathrm{PaO}_{2}$ of $50-80 \mathrm{~mm}$ $\mathrm{Hg}$; birth weight 500-2000 g; less than 12 hours of age; no contraindications to steroid treatment, such as bleeding tendency, hypertension, hyperglycaemia, or active infection; and no lethal congenital malformation. All infants received bovine surfactant (Surfactant TA) $100 \mathrm{mg} / \mathrm{kg}$ up to a maximum of four doses. Each infant received either dexamethasone $0.25 \mathrm{mg} / \mathrm{kg}$ or saline placebo every 12 hours for a total of six doses. Subsequent corticosteroid treatment for chronic lung disease was permitted after 7 days of age at the clinician's discretion.

A total of 248 infants were enrolled in the study (132 received dexamethasone, and 116 received placebo). Cranial ultrasound examinations were performed on day 1 of life, at age 


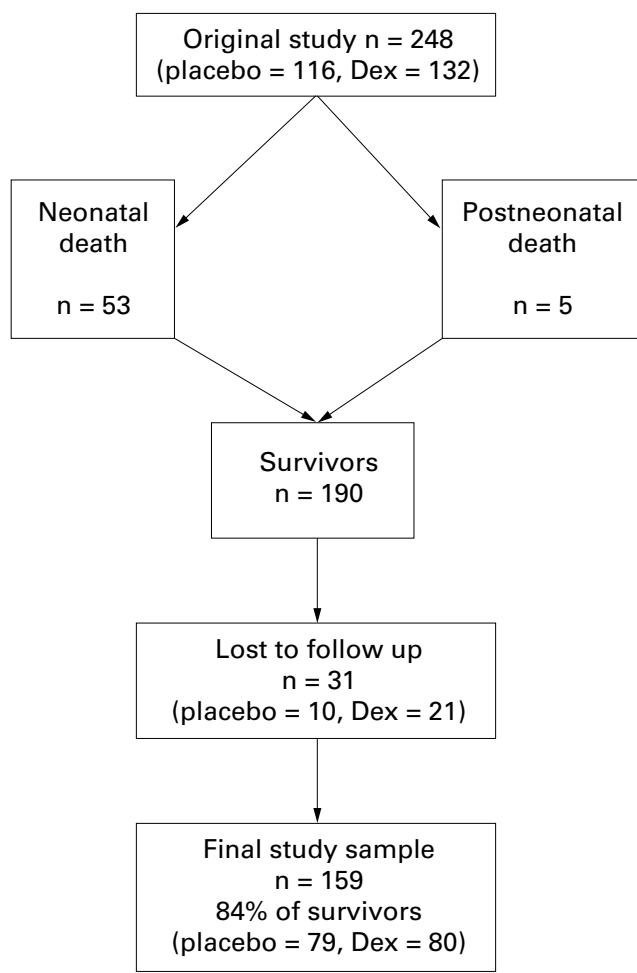

Figure 1 Description of origins of study sample. Dex, dexamethasone.

1 and 6 weeks, and as clinically indicated. No differences were found between the groups with respect to survival to discharge or the incidence of chronic lung disease as assessed by the requirement for supplemental oxygen at 28 days and 36 and 40 weeks corrected gestational age. Fewer of the treated infants required mechanical ventilation at age 3 days, but this difference was not significant by 7 days of age. Adverse effects such as gastrointestinal haemorrhage, hypertension, and hyperglycaemia were more common in dexamethasone treated infants. No cases of gastrointestinal perforation were noted.

FOLLOW UP STUDY

Fifty three infants died during the neonatal period and five children died after discharge (four from the group receiving placebo, one receiving dexamethasone). The causes of postneonatal death included chronic lung disease (11 months), an acute respiratory illness without chronic lung disease ( 7 months), familial neurodegenerative syndromes (12, 36 months), and convulsions of unknown cause ( 5 months). Data were incomplete or absent for 31 of the 190 survivors (21 receiving dexamethasone and 10 receiving placebo). No significant differences were found in birth weight, gestational age, and perinatal and neonatal characteristics between study children and those children with incomplete or absent data (not shown). The final study sample consisted of 159 children $(83.6 \%$ of survivors; 80 had received dexamethasone, 79 had received placebo; fig 1).

Data were obtained between October 1998 and March 1999 from neonatal follow up clinics and child development centres. Supplemen- tary information was received from the child's paediatrician or family practitioner and from the parents. Diagnoses and developmental data were based on the most recent examination by a paediatric neurologist. Both the examining doctors and the investigators were blinded to the treatment (dexamethasone or placebo) that the child had received in the study. Abnormal neurological findings included cerebral palsy in its various forms, mild generalised hypotonia of unknown origin $(n=1)$, and "soft signs", which were defined as minor or inconsistent abnormalities of tone or reflexes and were seen in one child in each group. As detailed Bailey, Griffith, or other developmental assessments were not available in all cases, investigators were asked to define developmental status as either normal, mildly abnormal, or severely abnormal. Severe abnormality referred to children with any of the following: motor disability who were not independently ambulatory, global retardation, deafness requiring hearing aids, and blindness. The mean (SD) age at assessment was 53 (18) months (range 24-71) for both placebo and dexamethasone treated groups.

STATISTICAL ANALYSIS

Statistical analyses were performed using SPSS for Windows. Student's $t$ test was used for comparison of continuous variables. For variables with pronounced skewness of distribution, the Mann-Whitney U-Wilcoxon Rank Sum Test was used. $\chi^{2}$ or Fisher's exact tests were used for categorical variables, and odds ratios and $95 \%$ confidence intervals were calculated. A logistic regression model was constructed for the major variables that influenced the incidence of neurological abnormality.

\section{Results}

PERINATAL CHARACTERISTICS

No significant differences were found between the groups in birth weight, gestational age, sex distribution, Apgar scores, mode of delivery, or antenatal steroid administration (table 1). Likewise, no differences were noted in the severity of the initial disease as assessed by the highest appropriate $\mathrm{FIO}_{2}$ and lowest $\mathrm{pH}$ and lowest blood pressure recorded in the first 12 hours, together with the age at initiation of mechanical ventilation, the age at first surfactant administration, and the grading of the severity of respiratory distress syndrome on the chest radiograph. ${ }^{14}$ The incidence of neonatal

Table 1 Perinatal characteristics of preterm infants receiving either a three day course of dexamethasone (Dex) or placebo

\begin{tabular}{llll}
\hline & $\begin{array}{l}\text { Placebo } \\
(n=79)\end{array}$ & Dex $(n=80)$ & $p$ Value \\
\hline Birth weight $(\mathrm{g})$ & $1204(360)$ & $1278(390)$ & 0.22 \\
Gestational age (weeks) & $29.3(2.6)$ & $29.2(2.6)$ & 0.81 \\
Sex (M/F) & $44 / 35$ & $47 / 33$ & 0.63 \\
Apgar at 5 min & $8(2)$ & $8(2)$ & 0.88 \\
Cesarean section & $52(66 \%)$ & $50(63 \%)$ & 0.50 \\
Antenatal steroids & & & \\
$\quad$ None & $56(71 \%)$ & $61(76 \%)$ & \\
$\quad$ partial & $9(11 \%)$ & $10(13 \%)$ & 0.52 \\
$\quad$ Complete & $14(18 \%)$ & $9(11 \%)$ & \\
\hline
\end{tabular}

Values are mean (SD) unless indicated otherwise. 
Table 2 Morbidity in the neonatal period in preterm infants receiving either a three day course of dexamethasone (Dex) or placebo

\begin{tabular}{lcllll}
\hline & Placebo $(n=79)$ & Dex (n=80) & $\begin{array}{l}\text { Odds ratio (95\% CI) } \\
\text { or p value }\end{array}$ \\
\hline ROP (all grades) & 28 & $(35 \%)$ & 32 & $(42 \%)$ & $1.21(0.64$ to 2.3$)$ \\
Sepsis/pneumonia & 35 & $(44 \%)$ & 34 & $(43 \%)$ & $0.93(0.5$ to 1.74$)$ \\
PDA & 22 & $(28 \%)$ & 17 & $(21 \%)$ & $0.70(0.34$ to 1.44$)$ \\
Pneumothorax/PIE & 8 & $(10 \%)$ & 7 & $(9 \%)$ & $0.99(0.33$ to 2.94$)$ \\
NEC & 7 & $(9 \%)$ & 6 & $(8 \%)$ & $0.84(0.27$ to 2.59$)$ \\
Ventilation (days) & 12 & $(15)$ & $8.4(13)$ & $\mathrm{p}=0.09$ \\
Duration of $\mathrm{O}_{2}$ (days) & 24 & $(33)$ & 25 & $(36)$ & $\mathrm{p}=0.97$ \\
Steroids for BPD (days) & $8.4(17)$ & $4.9(13)$ & $\mathrm{p}=0.15$ \\
Steroids for BPD (n) & $26(33 \%)$ & 17 & $(21 \%)$ & $\mathrm{p}=0.1$ \\
$\mathrm{O}_{2}$ at 36 weeks GA & 11 & $(14 \%)$ & 11 & $(14 \%)$ & $0.99(0.40$ to 2.42$)$ \\
$\mathrm{O}_{2}$ at 40 weeks GA & 6 & $(8 \%)$ & 6 & $(8 \%)$ & $0.99(0.31$ to 3.19$)$
\end{tabular}

Values are mean (SD) unless otherwise indicated.

ROP, Retinopathy of prematurity; PDA, patent ductus arteriosus; PIE, pulmonary interstitial emphysema; NEC, necrotising enterocolitis; BPD, bronchopulmonary dysplasia; GA, gestational age.

Table 3 Cranial ultrasound findings in the neonatal period in preterm infants receiving either a three day course of dexamethasone (Dex) or placebo

\begin{tabular}{lccl}
\hline & $\begin{array}{l}\text { Placebo } \\
n=79\end{array}$ & Dex $n=80$ & $\begin{array}{l}\text { Odds ratio } \\
\text { (95\% CI) }\end{array}$ \\
\hline IVH & $9(11 \%)$ & $3(4 \%)$ & $0.3(0.1$ to 1.1$)$ \\
$\quad$ Grade I & $10(13 \%)$ & $7(9 \%)$ & $0.7(0.2$ to 1.8$)$ \\
Grade II & $7(9 \%)$ & $5(6 \%)$ & $0.7(0.2$ to 2.2$)$ \\
Grade III & $1(1 \%)$ & $2(2 \%)$ & $1.9(0.2$ to 19$)$ \\
Grade IV & $27(34 \%)$ & $17(21 \%)$ & $0.53(0.3$ to 1.1$)$ \\
IVH All grades & $8(13 \%)$ & $13(22 \%)$ & $1.70(0.68$ to 4.5$)$ \\
PVL &
\end{tabular}

IVH, Intraventricular haemorrhage; PVL, periventricular leucomalacia.

morbidities such as chronic lung disease, patent ductus arteriosus, air leak, sepsis, and necrotising enterocolitis was similar in the two groups (table 2).

Dexamethasone treated infants had less intraventricular haemorrhage and more periventricular leucomalacia (PVL) than placebo treated infants but these findings were not statistically significant (table 3 ).

NEUROLOGICAL AND DEVELOPMENTAL OUTCOME As shown in table 4, the incidence of cerebral palsy was significantly higher in dexamethasone treated infants. Spastic diplegia was significantly more common in dexamethasone

Table 4 Neurological outcome in preterm infants receiving either a three day course of dexamethasone (Dex) or placebo

\begin{tabular}{lcll}
\hline & Placebo $n=79$ & Dex $n=80$ & Odds ratio (95\% CI) \\
\hline Normal & $66(84 \%)$ & $40(50 \%)$ & $0.22(0.12 \text { to } 0.43)^{\star}$ \\
Abnormal-total & $12(15 \%)$ & $39(49 \%)$ & $4.62(2.38 \text { to } 8.98)^{\star}$ \\
Spastic diplegia & $5(6 \%)$ & $22(28 \%)$ & $4.45(1.95 \text { to } 10.15)^{\star}$ \\
Spastic quadriplegia & $7(9 \%)$ & $13(16 \%)$ & $1.95(0.77$ to 4.96$)$ \\
Hemiplegia & 0 & $3(4 \%)$ & $7.49(0.77$ to 73$)$ \\
Hypotonia & 0 & $1(1 \%)$ & $7.3(0.14$ to 99$)$ \\
Soft signs & $1(1 \%)$ & $1(1 \%)$ & $0.99(0.06$ to 15.9$)$ \\
\hline
\end{tabular}

^Statistically significant difference.

Table 5 Developmental, vision, and hearing status in preterm infants receiving either a three day course of dexamethasone (Dex) or placebo

\begin{tabular}{lcll}
\hline & Placebo $(n=79)$ & Dex $(n=80)$ & Odds ratio (95\% CI) \\
\hline Normal development & $56(71 \%)$ & $36(45 \%)$ & $0.35(0.19 \text { to } 0.65)^{\star}$ \\
Abnormal development & $23(29 \%)$ & $44(55 \%)$ & $2.87(1.53 \text { to } 5.38)^{\star}$ \\
Mild abnormality & $12(15 \%)$ & $26(33 \%)$ & $2.57(1.24 \text { to } 5.3)^{\star}$ \\
Severe abnormality & $11(14 \%)$ & $18(22 \%)$ & $1.77(0.79$ to 3.95$)$ \\
Vision & & & \\
$\quad$ Normal & $66(85 \%)$ & $62(78 \%)$ & $0.68(0.31$ to 1.49$)$ \\
$\quad$ Glasses & $7(9 \%)$ & $6(8 \%)$ & $0.84(0.27$ to 2.59$)$ \\
$\quad$ Strabismus & $4(5 \%)$ & $8(10 \%)$ & $2.02(0.62$ to 6.53$)$ \\
$\quad$ Blind & $1(1 \%)$ & $3(4 \%)$ & $2.74(0.38$ to 19$)$ \\
Deafness & 0 & $1(1 \%)$ & $7.3(0.14$ to 99$)$ \\
\hline
\end{tabular}

^Statistically significant difference.
Table 6 Birth weight and gestational age distribution in all infants and in those with cerebral palsy

\begin{tabular}{lll}
\hline & $\begin{array}{l}\text { Gestational age } \\
\text { (weeks) }\end{array}$ & Birth weight $(g)$ \\
\hline All survivors & $29.3(2.6)$ & $1242(377)$ \\
All CP & $28.7(2.3)$ & $1190(340)$ \\
CP + PVL & $28.4(1.8)$ & $1202(352)$ \\
CP + IVH & $28.3(2.4)$ & $1084(330)$ \\
CP + normal US & $29.2(2.7)$ & $1202(301)$ \\
\hline
\end{tabular}

Values are mean (SD).

$\mathrm{CP}$, cerebral palsy; PVL, periventricular leucomalacia; IVH, intraventricular haemorrhage; US, ultrasound.

treated children, but the difference in the incidence of spastic quadriplegia did not quite meet statistical significance. Developmental delay was significantly more common in dexamethasone treated infants (table 5). No differences were found in visual or hearing problems between the groups (table 5).

RELATION BETWEEN NEONATAL ULTRASOUND ABNORMALITIES AND NEUROLOGICAL OUTCOME As expected, abnormal cranial ultrasound findings in the neonatal period correlated highly with abnormal neurological outcome. All 21 infants with PVL, 11 of 29 (38\%) infants with intraventricular haemorrhage grades I-II, and eight of $15(53 \%)$ with intraventricular haemorrhage grades III-IV developed cerebral palsy.

Eleven $(22 \%)$ of the 51 children with cerebral palsy had normal neonatal ultrasound scans. All 11 of these infants were treated with dexamethasone. This group of infants did not differ from the remainder of the study sample or from the other children with cerebral palsy in terms of perinatal characteristics, severity of initial disease, or neonatal morbidity patterns.

No significant differences were found in birth weight and gestational age between the subgroups of children with cerebral palsy, namely those with PVL, intraventricular haemorrhage, or normal neonatal ultrasound examinations (table 6).

RISK FACTORS

To detect risk factors that may be associated with abnormal neurological outcome, a logistic regression model was constructed. Independent variables included all the variables in tables 1-3 together with blood gas values and ventilation variables before and after surfactant administration and at age 24 hours, 3, and 7 days. When a univariate analysis was used, $\mathrm{PCO}_{2}$ values were slightly lower at 72 hours of age in dexamethasone treated than placebo treated infants (34 (8) v 39 (7) respectively; $\mathrm{p}=0.0001)$ and in children who subsequently developed neurological handicap (normal 37 (8) $v$ handicap 34 (7); $\mathrm{p}=0.031$ ). However, in the multiple logistic regression model, only early dexamethasone treatment and PVL were statistically significant predictors of abnormal neurological outcome (dexamethasone: $\mathrm{p}=0.0006 ;$ PVL: $\mathrm{p}=0.0002)$.

\section{Discussion}

This study has shown an increased incidence of cerebral palsy that may be related to the administration of dexamethasone in the early postnatal period. 
Two other large randomised controlled trials of postnatal dexamethasone treatment have reported adverse long term follow up data. Yeh et $a l^{12}$ showed a significant increase in neuromotor dysfunction at age 2 years in infants treated with a four week course of dexamethasone begun before 12 hours of age (dexamethasone $25 / 63(40 \%) v$ placebo $12 / 70(17 \%)$ ). O'Shea et $a l^{13}$ showed considerably more cerebral palsy (dexamethasone 12/48 (25\%) v placebo $3 / 45(7 \%)$ ) and abnormal neurological examinations (dexamethasone 20/48 (45\%) v placebo $8 / 45(16 \%)$ ) at age 1 year after a 42 day course of dexamethasone begun after 2 weeks of age.

Three additional studies of postnatal dexamethasone treatment have produced inconclusive results. Cummings et $a l^{15}$, in a small study, showed less abnormal neurodevelopmental outcome at age 15 months in infants treated with a 42 day course (2/9) of dexamethasone after age 2 weeks compared with infants treated with an 18 day course (7/9) or placebo (3/5). Jones $e t a l^{16}$ studied the effects of a one week course of dexamethasone administered to infants requiring supplemental oxygen after 2 weeks of age. No difference was found in the incidence of cerebral palsy at age 3 years (dexamethasone 20/100 (20\%) v placebo 18/109 $(17 \%))$. Almost half of the infants in the placebo group subsequently received steroids, thus limiting the discriminatory power of the study. Vincer et $a l^{17}$ reported as an abstract a small study $(\mathrm{n}=17)$ of a six day course of dexamethasone administered after 28 days of age in which no effect was seen on the incidence of cerebral palsy (dexamethasone 4/9 $v$ placebo $2 / 8$ ).

None of the above studies reported an increase in cranial ultrasound abnormalities in the newborn period. However, the studies of O'Shea $e t a l^{13}$ and Noble-Jamieson et $a l^{18}$ (no follow up data) and this study have all shown a non-statistically significant trend towards more PVL in dexamethasone treated infants. Studies with a larger sample size, such as the current open study of early corticosteroid treatment (OSECT) trial, may be able to define further the relation between dexamethasone treatment and the incidence of PVL.

In our study, $22 \%(n=11)$ of the children with cerebral palsy had normal cranial ultrasound and all were treated with dexamethasone. Although this is a noteworthy finding, the relation between dexamethasone and the outcome is unclear. Laboratory and clinical studies have shown evidence of both detrimental and beneficial effects of dexamethasone on the neonatal nervous system. ${ }^{19-23}$

Recently, Baud and coworkers ${ }^{24}$ have reported that antenatal dexamethasone treatment is associated with a higher incidence of PVL than either antenatal betamethasone or no antenatal steroid treatment. One possible explanation for this finding is the possible neurotoxic effects of the sulphite preservative in the dexamethasone. ${ }^{25}$ The preparation used in our study likewise contained sodium meta- bisulphite in a concentration of $0.155 \mathrm{mg} / \mathrm{mg}$ dexamethasone. Clearly, this requires further study.

The acute effects of dexamethasone treatment in the neonatal period have been extensively studied. Halliday ${ }^{1}$ reviewed 25 randomised clinical trials of systemic dexamethasone treatment at three different postnatal ages: early (<96 h), moderately early (7-14 days), and delayed ( $>3$ weeks). Short term beneficial effects of improved gas exchange and lung mechanics were seen with administration at all ages. Reduction in chronic lung disease at age 28 days and 36 weeks was seen with early and moderately early treatment. A reduction in neonatal mortality was only seen with moderately early use in which there was one extra survivor for every 16 babies treated.

A number of limitations in our study design may influence the interpretation of the data. (a) The children were examined by a number of neurologists and developmental paediatricians and not by a single investigator. Although this may limit the interpretation of the developmental assessments, it is unlikely to influence the reported incidence of cerebral palsy at age 4 years, and thus the main finding of the study should not be affected. (b) No information is available on the incidence of chorioamnionitis, which is a potential confounding variable for the development of PVL and cerebral palsy. Related variables such as the incidence of premature rupture of membranes and neonatal sepsis, together with the severity of the initial disease, were not significantly different in the two groups. However, the interaction between chorioamnionitis and dexamethasone treatment will need to be looked at in other studies. (c) The administration of steroids after age 7 days for treatment of chronic lung disease is also a potential confounding variable. However, no significant difference was found in the late use of steroids in the two study groups. In addition, the incidence of cerebral palsy and/or developmental delay was not significantly different in children who had or had not received late steroids. This was true for the whole sample, as well as for dexamethasone and placebo treated subgroups (data not shown). (d) A potential limitation of follow up studies is the percentage of the subjects for whom valid data were obtained. Sackett et $a l^{26}$ states that, for a study to withstand a worst case analysis of its validity, at least $80 \%$ of the cases must have reported data. In this study, data on the major outcome variables were available in $84 \%$ of the cases. (e) Another issue of importance is the minimum age at which reliable follow up data can be obtained. As recommended by $\mathrm{Hack}^{27}$, we viewed 2 years as the minimum valid age and, indeed, the mean age at follow up was 53 months.

Thus, despite the limitations, this study offers a word of caution. On the one hand, dexamethasone is a powerful potentially life saving treatment for neonatal chronic lung disease. On the other hand, this and other studies raise the possibility of detrimental long term effects. It is critical that further studies of the use of dexamethasone and other steroids in the 
neonatal period should include long term neurodevelopmental follow up.

We wish to thank the doctors and nurses in each of the study centres and follow up clinics who conducted the study and collected the data.

1 Halliday HL. Clinical trials of postnatal corticosteroids: inhaled and systemic. Biol Neonate 1999;76(suppl 1):2940 .

2 Shinwell ES, Karplus M, Zmora E, et al. Failure of early postnatal dexamethasone to prevent chronic lung disease in infants with respiratory distress syndrome. Arch Dis Child Fetal Neonatal Ed 1996; 74:F33-7.

3 Baden M, Bauer CR, Cole E, Klein G, Taeusch HW, Stern L. A controlled trial of hydrocortisone therapy in infants with respiratory distress syndrome. Pediatrics 1972;50:526-34

4 Kopleman A, Moise A, Holbert D. A single dose of dexamethasone (Dex) given at delivery to infants $<28$ weeks gestation results in improved lung function, early extubation, higher BP and less PDA [abstract 1046]. Pediatr Res 1998;43:180.

5 Rastogi A, Akintorin SM, Bez ML, Morales P, Pildes PS. A controlled trial of dexamethasone to prevent bronchopulmonary dysplasia in surfactant-treated infants. Pediatrics 1996;98:204-10.

6 Sanders RJ, Cox C, Phelps DL, Sinkin RA. Two doses of early intravenous dexamethasone for the prevention of early intravenous dexamethasone for the prevention of
bronchopulmonary dysplasia in babies with respiratory bronchopulmonary dysplasia in babies with
distress syndrome. Pediatr Res 1994;36:122-8.

7 Sinkin RA, Sweck HS, Horgan MJ, Gallaher KJ, Cox C, Phelps DL, Rochester Clinical Trial Group. Early intravenous dexamethasone (Dex) for the prevention of BPD in surfactant-treated babies with RDS [abstract 1138]. Pediatr Res 1998;43:195.

8 Suske G, Oestreich K, Varnbolt V, Lasch P, Kachel W. Influence of early postnatal dexamethasone therapy on ventilator dependency in surfactant-substituted preterm infants. Acta Paediatr 1996;85:713-18.

9 Tapia JL, Ramirez R, Cifuentes J, et al. The effect of early dexamethasone administration on bronchopulmonary dysplasia in preterm infants with respiratory distress syndrome. F Pediatr 1998;132:48-52.

10 Yeh TF, Torre JA, Rastogi A, Anyebuno MA, Pildes RS Early postnatal dexamethasone therapy in premature infants with respiratory distress syndrome: a double-blind infants with respiratory distress syndrome: a

11 Yeh TF, Lin YJ, Hsieh WS, et al. Early postnatal dexamethasone therapy for the prevention of chronic lung disease in preterm infants with respiratory distress syndrome: a multicenter, clinical trial. Pediatrics 1997;100:e3

12 Yeh TF, Lin YJ, Huang CC, et al. Early dexamethasone therapy in premature infants: a follow-up study. Pediatrics 1998;101:e7.
13 O'Shea TM, Kothadia JM, Klinepeter KL, et al. Randomized placebo-controlled trial of a 42-day tapering course of dexamethasone to reduce the duration of ventilator dependency in very low birth weight infants: outcome of study participants at 1-year adjusted age. Pediatrics 1999;104:15-21.

14 Giedion A, Haefliger H, Dangel P. Acute pulmonary x-ray changes in hyaline membrane disease treated with artificial ventilation and positive end-expiratory pressure. Pediatr Radiol 1973;1:145-52.

15 Cummings JJ, D'Eugenio MA, Gross SJ. A controlled trial of dexamethasone in preterm infants at high risk for bronchopulmonary dysplasia. N Engl f Med 1989;320:150510.

16 Jones R, Wincott E, Elbourne D, Grant A. Controlled trial of dexamethasoone in neonatal chronic lung disease: a 3-year follow-up. Pediatrics 1995;96:897-906.

17 Vincer MJ, Allen AC. Double blind randomized controlled trial of 6-day pulse of dexamethasone for very low birth weight infants (VLBW < 1500 grams) who are ventilator dependent at 4 weeks of age [abstract]. Pediatr Res 1998;43:201A.

18 Noble-Jamieson CM, Regev R, Silverman M. Dexamethasone in neonatal chronic lung disease: pulmonary effects and intracranial complications. Eur $\mathcal{F}$ Pediatr 1989;148: 365-7.

19 Tsubota S, Adachi N, Chen J, Yorozuya T, Nagaro T, Arai $\mathrm{T}$. Dexamethasone changes brain monamine metabolism and aggravates ischemic neuronal damage in rats. Anesthesiology 1999;90:515-19.

20 Benesova O, Pavlik A. Perinatal treatment with glucocorticoids and the risk of maldevelopment of the brain. Neuropharmacology 1989;28:89-97.

21 Vicedomini JP, Nonneman AJ, DeKosky ST, Scheff SW, Perinatal glucocoticoids disrupt learning: a sexually dimorphic response. Physiol Behav 1986;36:145-9.

22 Papile L-A, Tyson JE, Stoll BJ, et al. A multicenter trial of two dexamethasone regimens in ventilator-dependent premature infants. N Engl f Med 1998;338:1112-18.

23 Tuor UI, Simone CS, Barks JD, Post M. Dexamethasone prevents cerebral infarction without affecting cerebral blood flow in neonatal rats. Stroke 1993;24:452-7.

24 Baud O, Foix-L-Helias L, Kaminski M, et al. Antenatal glucocorticoid treatment and cystic periventricular leukomalacia in very premature infants. $N$ Engl $\mathcal{F} \mathrm{Med}$ 1999;341:1190-6.

25 Leist M, Marshall KA, Jenner P, Halliwell B. Toxic effects of sulfite in combination with peroxynitrite on neuronal cells. f Neurochem 1998;71:2431-8.

26 Sackett DL, Richardson WS, Rosenberg W, Haynes RB. Evidence-based medicine. How to practice and teach EBM. New York: Churchill-Livingstone 1997:95.

27 Hack M. Follow-up for high risk neonates. In: Fanaroff AA, Martin RJ, eds. Neonatal-perinatal medicine. 6th ed. St Louis: Mosby, 1997. 